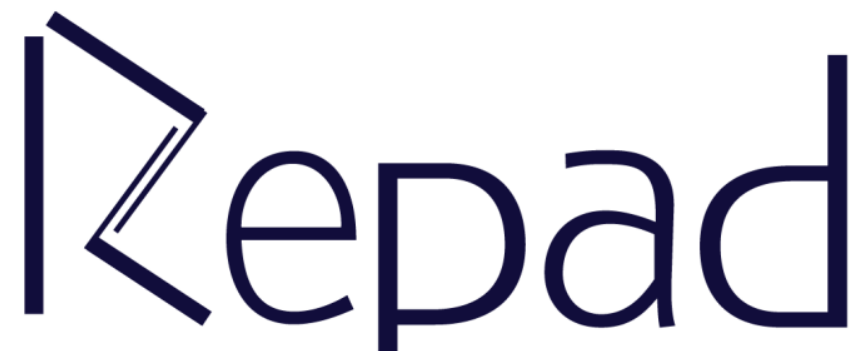

Vol. 1, N. 1 Dezembro/2017

Revista Estudos e

Pesquisas em Administração

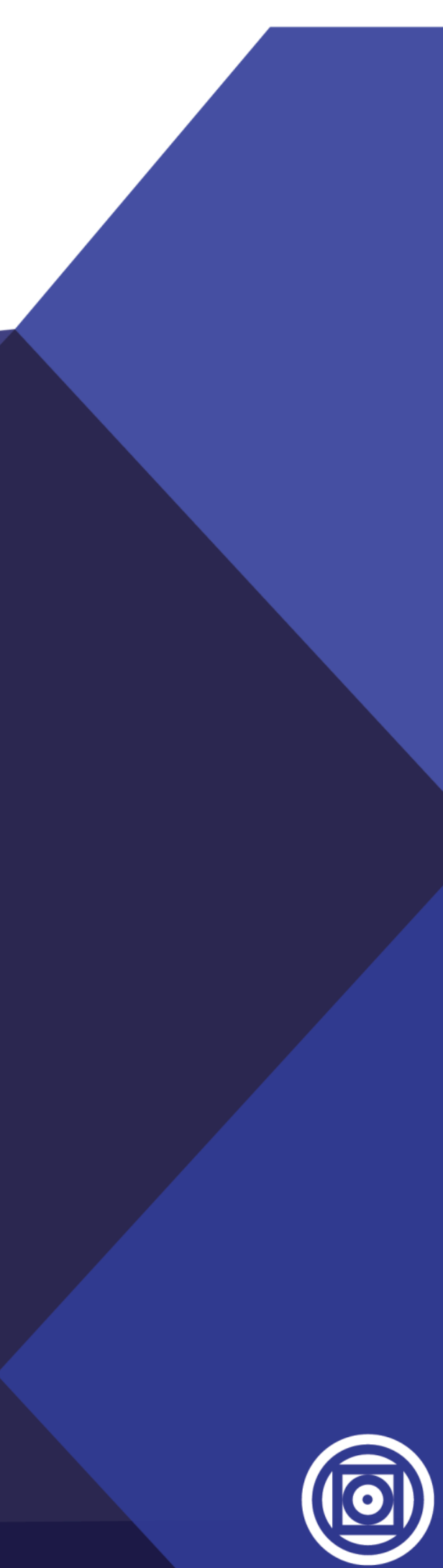




\title{
VENDA DE ATIVOS PÚBLICOS EM DIFERENTES FORMATOS DE LEILÃO
}

\author{
Ricardo da Costa Nunes \\ Selene Peres Peres Nunes
}

\section{RESUMO}

Este trabalho apresenta uma resenha da literatura sobre leilões, a partir da clássica nomenclatura de Vickrey, procurando determinar a modalidade que tende a gerar maior resultado em termos de receita. O objetivo da análise, aplicada ao processo de privatização brasileiro, seria determinar se o leilão inglês é de fato aquele que maximiza receita, atendendo aos anseios do governo, e oferecer sugestões para o aperfeiçoamento do processo. Conclui-se que o leilão de lance selado tende a oferecer melhores resultados por mitigar a praga do vencedor e, ainda, que com aumento do número de participantes e maior divulgação de informações, a receita também tende a ser maior.

Palavras-chave: Leilão, receita, privatização, lucro

\section{SALE OF PUBLIC ASSETS IN DIFFERENT AUCTION FORMATS}

\begin{abstract}
This paper presents a research about auctions. Taking Vickrey's classic terminology as a starting point, it attempts to determine the auction format that tends to produce better results in terms of revenue. The objective of this analysis, that could be applied to the Brazilian privatization process for example, is to verify whether the English Auction is the one that maximizes revenues and to offer suggestions on the improvement of the process. It can be concluded that the sealed auction tends to offer better results because it diminishes the "winner's curse" and, besides, that revenues also tend to increase along with the number of participants and as relevant information is published.
\end{abstract}

Keywords: Auction, revenue, privatization, profit

\section{INTRODUÇÃO}

O processo de privatização de ativos públicos, intensificado em vários países nas décadas de 80 e 90, volta a ser contemplando no Governo Temer como uma alternativa de receita governamental. O processo de privatização tem adotado basicamente dois mecanismos de venda: leilão e distribuição a preço fixo. Segundo Vickers e Yarrow (1995), a Inglaterra utilizou a distribuição a preço fixo como plataforma política, pois falava-se do processo em que os trabalhadores se tornam sócios da empresa como uma "socialização do capitalismo". O relatório do Banco Mundial (World Bank (1989)) também aponta esse procedimento como o mais aceitável politicamente porque os governos dos países que tem realizado a privatização sem a participação maciça da população tem sofrido severa oposição. 
Contudo, ainda que o governo brasileiro conseguisse ampliar o mercado acionário para disseminar a venda de ações públicas, o resultado em termos de geração de receita não seria mais favorável do que o de um leilão porque, na distribuição a preço fixo, os preços em geral são baixos para contemplar o maior número possível de compradores. Isto é o que parece indicar a literatura sobre leilões que tem se desenvolvido desde a publicação do paper clássico de William Vickrey (1961). Assim, o fato de ter o Conselho Nacional de Desestatização - CND optado pelo leilão na maioria dos casos, embora a legislação vigente ${ }^{1}$ autorize a venda de ações e quotas de empresas públicas de ambas as formas, não chega a ser surpreendente. A maximização de receita, um dos principais objetivos do processo de privatização brasileiro, parece ser mais facilmente alcançada no leilão, que ainda tende a corrigir eventuais falhas de subavaliação do preço mínimo pois a concorrência no próprio mercado faz elevar o preço. Essa é a razão pela qual torna-se relevante determinar a modalidade de leilão capaz de proporcionar maior receita na venda dos ativos públicos.

\section{Modalidades de leilão e maximização de receita}

O objetivo desta seção é apontar as regras que maximizam a receita do vendedor no leilão de privatização, oferecendo indicações de aperfeiçoamentos para o processo de privatização brasileiro. Para tanto, é apresentado um survey da literatura sobre teoria dos leilões, sob a ótica do potencial de geração de receita das diferentes modalidades de leilão. Procura-se caracterizar a modalidade de leilão ótima, isto é, aquela que propiciará a maior receita para o vendedor, em diferentes níveis de complexidade: modelo simplificado e modelo complexo.

Modelo Simplificado

Visando caracterizar o leilão ótimo" ou "leilão maximizador de receita", Vickrey (1961) analisa os leilões abertos e os leilões de lance selado, sob a ótica da receita esperada para o vendedor, a partir das seguintes hipóteses:

a) O comprador é neutro ao risco. Entende-se por neutralidade ao risco, a ausência de comportamento econômico determinado pela preocupação de que o lance proposto arremate o bem, mas, por ser elevado, gere prejuízo.

b) O produto é de valor privado. Quando o produto a ser leiloado é de valor privado ou subjetivo, o comprador não se defronta com a preocupação de estar possivelmente oferecendo um lance acima do valor de mercado, pois a compra não tem por finalidade a revenda.

c) Os lances são independentes. A independência dos lances se traduz no fato de que cada licitante se preocupa somente com os seus lances, não importando as propostas dos concorrentes. Ou ainda, segundo Riley e Samuelson (1981), a independência se traduz no fato de que cada indivíduo decide o montante máximo que está disposto a pagar independentemente dos outros, pois não tem certeza sobre os demais valores de reserva.

d) A distribuição de informação é simétrica. Por distribuição simétrica de informações, entendese que o conhecimento sobre o produto a ser leiloado é o mesmo para todos os concorrentes. A este respeito Hirsherleifer (1988, p. 561) afirma: "Os indivíduos não têm certeza apenas sobre o valor da mercadoria leiloada e/ou sobre o retorno alcançável a partir de seus próprios lances". (tradução livre)

Além das suposições acima, por desenvolver um modelo que emprega a Teoria dos Jogos, Vickrey assume ainda que: a) os agentes não são cooperativos; b) cada lance proposto é uma função crescente das avaliações individuais; c) há transparência no mercado; d) o conjunto de

\footnotetext{
${ }^{1}$ Ver os artigos 34 e 35 do Decreto 2.594/94, em Brasil (1998).
} 
estratégias idênticas forma uma estratégia ótima, a qual representa o equilíbrio de Nash do jogo competitivo.

O resultado da adoção conjunta de todas essas hipóteses é que a estratégia de lance ótima para um determinado proponente deve também ser uma estratégia ótima para qualquer outro proponente. Além disso, cada indivíduo tem pleno e equivalente conhecimento do valor da mercadoria.

Tomando tais pressupostos, Vickrey demonstra que os quatro tipos básicos de leilão produzem, em média, a mesma receita esperada pelo vendedor porque a estratégia ótima para os proponentes seria equivalente e, conseqüentemente, o preço de venda seria, em média, o mesmo. A esta teoria convencionou-se chamar de Teoria da Equivalência da Receita. A conclusão fundamental parece ser a de que o formato de leilão escolhido é irrelevante. ${ }^{2}$ Segundo Bartolini e Cottarelli (1994), este resultado é possível porque, em virtude das hipóteses assumidas por Vickrey (1961), não há atuação da praga do vencedor ${ }^{3}$.

Corroborando as conclusões de Vickrey (1961), McAfee e McMillan (1987) e Milgrom e Weber (1982a) admitem que, não obstante as diferenças existentes nos procedimentos dos leilões dos tipos inglês, holandês, de primeiro preço e de segundo preço, os quatro formatos de leilões produzem, em média, o mesmo resultado. Milgrom e Weber (1982a, p.1093) ratificam as proposições dos autores citados argumentando que, em situações de valor privado e de independência entre os lances, os quatro formatos de leilão são equivalentes porque a estratégia ótima para os proponentes será a mesma e, consequentemente, também o preço de venda: "No equilíbrio simétrico do leillões inglês, holandês, primeiro preço e segundo preço, as condições do teorema estão satisfeitas. Consequentemente, o preço de venda esperado é o mesmo para todos os mecanismos”. Ou ainda: “(...) é que no modelo de valores privados independentes, os quatro modelos de leilão levam a receitas esperadas idênticas para o vendedor", conforme Milgrom e Weber (1982a, p. 1092, tradução livre)

Ainda, segundo Bickchandani e Huang (1993), a despeito dos leilões de primeiro preço (discriminatório) e de segundo preço (onde se paga um preço uniforme) possuírem sistemáticas de operacionalização distintas, a tendência é de que haja equivalência de receita. No leilão de segundo preço, os ganhadores pagam à mais alta oferta perdedora um preço uniforme, enquanto que num leilão de primeiro preço os ganhadores pagam seus próprios lances. Contudo, se por um lado seria razoável esperar que, por esta razão, o leilão de segundo preço produzisse menor receita para o vendedor, por outro lado, os proponentes em um leilão de segundo preço tendem a licitar mais agressivamente por estarem cientes dos procedimentos do leilão. Estes aspectos tenderiam a neutralizar as vantagens de um e outro tipo de leilão.

Holt (1980), num contexto de lance para um único bem (unidade indivisível), também mostra que a expectativa de renda para o vendedor é idêntica nos dois tipos de leilão quando os proponentes são neutros ao risco. Para Harris e Raviv (1981, p. 1494, tradução livre), a neutralidade dos compradores ao risco coaduna-se com a Teoria da Equivalência da Receita entre os leilões de lance selado e os leilões orais: "Ocorre que o leilão ideal é equivalente em termos de receita esperada ao seguinte leilão oral padrão, conforme Harris e Raviv (1981, p. 1495, tradução livre), também asseguram a equivalência de receita entre os leilões de segundo e primeiro preço:"(...) nossos resultados sugerem que quando os compradores são neutros em risco, os leilões competitivos e discriminatórios são mecanismos ideais”.

\footnotetext{
${ }^{2}$ Segundo Paul Milgrom, num leilão oral, em situação de incerteza, esta equivalência não se mantém porque cada participante pode ser capaz de aprender sobre o comportamento dos demais, como previsto na teoria das expectativas adaptativas.
}

${ }^{3}$ A praga do vencedor será explicada posteriormente. 


\section{Modelo Complexo}

O desenvolvimento posterior da teoria de Vickrey mostrou que, sob condições mais restritivas e realistas, a equivalência de receita entre os diversos formatos de leilão não se mantém.

Cox, Smith e Walker (1984) realizaram testes sobre as hipóteses e proposições da teoria de Vickrey, que foram denominados "Testes Harris Raviv". Alguns resultados merecem ser destacados, dentre os quais:

1. a rejeição da proposição de que os ofertantes são homogêneos em 24 dos 28 experimentos (p. 1006), o que implica que não se pode concluir que todos os agentes são neutros ao risco (p.985).

2. o desconhecimento dos efeitos das atitudes de risco nas realizações de lances (p. 1009)

Com o intuito de aperfeiçoar a teoria dos leilões, diversos modelos teóricos têm sido propostos com a exclusão de algumas das mencionadas hipóteses simplificadoras. Milgrom e Weber (1982a), Maskin e Riley (1985), Harris e Raviv (1981), dentre outros, adotam suposições mais verossímeis sobre o comportamento do licitante e o acesso a informações. Se os proponentes são avessos ao risco, por exemplo, Riley e Samuelson (1981) também tem mostrado que a Teoria da Equivalência da Receita pode ser compreendida antes como um caso particular.

Assim, o estudo de leilões parece requerer a adoção de hipóteses mais realistas que a partir daqui serão analisadas.

a) Assimetria de informações

Até agora, assumia-se simetria das informações e transparência do mercado, o que se traduzia no fato de que cada indivíduo e seus concorrentes tinham pleno e equivalente conhecimento do valor da mercadoria. A assimetria da informação ocorre quando, no caso dos leilões, um dos proponentes tem maior quantidade ou melhor qualidade de informação que os outros, ou seja, tem informação privilegiada. Esse é um problema particularmente relevante não apenas nos leilões, mas também no setor financeiro e em outras áreas da atividade econômica e ocorre porque os custos de coletar toda a informação necessária são muito elevados ou porque uma das partes tem posição privilegiada do ponto de vista da obtenção da informação.

A assimetria da informação torna muito difícil para cada licitante avaliar adequadamente toda a informação disponível numa situação em que os custos de erros de informação são excessivamente elevados. Assim, a existência de problemas de informação assimétrica gera uma falha de mercado que impede que os preços funcionem como mecanismo de ajuste da economia.

Hendricks e Porter (1988, p. 874, tradução livre) realizaram estudos demonstrando haver forte correlação entre a informação disponível dos adquirentes de terras em leilão e a margem de lucro obtida na exploração de petróleo nessas terras. Assim, quando terras passíveis de conterem reservas de petróleo vão a leilão, as firmas vizinhas, por possuírem maior conhecimento que as não-vizinhas, têm maior probabilidade de acertar nas suas previsões. Por outro lado, em terras sobre as quais não há conhecimento geológico prévio, a distribuição das informações é relativamente simétrica e a margem de lucro tende a ser menor: “...parece que a 
empresa vizinha conseguiu identificar quais os tratos de exploração que mais provavelmente poderiam conter o petróleo e que poderia explorar esse conhecimento para obter lucros acima."

$\mathrm{O}$ fato de haver assimetria de informações e pouca transparência no mercado faz com que o indivíduo que deseja vencer, para assegurar a compra, tenda a realizar um lance mais elevado do que o próprio valor do bem leiloado, o que pode reduzir o seu lucro ou até mesmo ocasionar prejuízo. Este fenômeno, conhecido como praga do vencedor, é definido por Kagel e Levin (1986, p. 394, tradução livre): "Falhas de julgamentos nos valores que vão a leilão são conhecidas como "curso do vencedor".

A praga do vencedor é amplamente conhecida como sendo um fenômeno em que o "sortudo" vencedor paga um preço acima valor do produto. Segundo Thiel (1988), a praga do vencedor revela que há avaliações viesadas e superavaliadas da mercadoria a ser leiloada, resultando em perda para o adquirente. $\mathrm{O}$ vencedor tende a ser o mais otimista ou o menos avesso ao risco relativamente ao preço do produto leiloado.

Em vista destes fatos, é razoável supor que, mesmo numa situação de independência entre os lances dos participantes e independentemente do tipo de leilão adotado, o indivíduo que só detiver informação de domínio público dificilmente terá condições de submeter propostas competitivas associadas a lucros positivos. Assim, a melhor atitude para o licitante seria não participar do leilão. Tal conclusão é compartilhada por Milgrom e Weber (1982b, p. 940, tradução livre) :" Todos os lucros obtidos pelos licitantes surgem como ganhos nas compras ou como resultado de especulações baseadas em boas informações privadas. Os especuladores mal informados só podem perder."

Diferentemente, a expectativa do comprador com informações exclusivas (inside information) é a obtenção de lucro. Segundo Hirsherleifer (1988, p. 567), são expressivos os incentivos dos potenciais compradores para buscar informação exclusiva: "Assim, os incentivos para obter informações privadas permanecem excessivos."

Assim, a assimetria de informações, que não havia sido considerada no modelo simplificado, tende a afetar o preço com que o bem é negociado no leilão e a aumentar a margem de lucro do comprador. "As frações dos tratos de terrenos perfurados e que continham o óleo eram substancialmente maiores do que os desconhecidos" (HIRSHERLEIFER, 1988, p. 865, tradução livre)

Como os leilões de ativos públicos envolvem risco e incerteza, a natureza das informações disponíveis é um elemento de crucial importância no processo de tomada de decisões de um investidor, uma vez que pode afetar significativamente a rentabilidade do leilão. $\mathrm{O}$ risco pode ser contornado pelos potenciais compradores mediante obtenção de informações sobre a atividade e a perspectiva de ganho da empresa. Portanto, cabe ao vendedor que tem acesso a algumas das informações dos compradores melhor informados, ou se ele mesmo as tem, aumentar o preço esperado com a divulgação das informações.

Caso o governo não desenvolva um programa extensivo divulgando informações sobre as empresas destinadas à venda, o público poderá acreditar que o produto não é bom. $\mathrm{O}$ conhecido modelo de carros usados (limões) de Akerlof (1970) fornece um exemplo de que a restrição de informação ao vendedor lhe traz prejuízo. Neste modelo, o vendedor sabe mais sobre a qualidade de seu carro que o comprador e o comprador sabe que o vendedor é muito bem informado. Consequentemente, o comprador se preocupa com a possibilidade de o carro estar sendo vendido porque é um "limão" e só compra se o vendedor lhe oferece um desconto.

A divulgação de informações pelo vendedor, em geral, objetiva promover um retorno ao contexto de simetria de informações, permitindo aumentar o preço de venda do bem. Contudo, este objetivo pode não ser atingido se há complementariedade entre as informações do vendedor e do comprador. No caso particular de assimetria em que as informações do vendedor são 
complementares às informações do comprador melhor informado, a divulgação de informações adicionais não altera o preço de venda porque o licitante melhor informado eleva o seu conhecimento sobre o produto e mantém sua posição de maior conhecedor sobre o bem a ser leiloado.

Segundo Kagel e Levin (1986), na ausência da praga do vencedor, o fornecimento de informações públicas ${ }^{4}$ reduz a incerteza e aumenta o preço do produto leiloado e a receita do vendedor. Contudo, quando há praga do vencedor, a divulgação de informações públicas resulta em média de lances vencedores mais baixos, o que pode reduzir a receita do vendedor.

A atuação da praga do vencedor varia de acordo com a situação. Há ocasiões em que os potenciais compradores não percebem que a praga do vencedor está atuando e a divulgação de informações contribui para aumentar o preço de venda dos produtos. Diferentemente, quando os potenciais compradores percebem que ela está atuando, a divulgação de informações pode não resultar em neutralização da praga do vencedor, porque a maior parte dos potenciais compradores pode acreditar que ainda que esteja bem informada, continuam a existir alguns compradores que estão melhor informados. Tal proposição foi reconhecida por Kagel e Levin (1986, p.394, tradução livre): "Fornecer informações públicas sobre o valor do item leiloado aumenta a receita do vendedor na ausência da praga do vencedor, mas produz o resultado contrário em sua presença."

Parece-nos que a ação da praga do vencedor é tão imprevisível quanto os indivíduos, o que explica a ambiguidade da sua ação. No entanto, de maneira geral, a divulgação de informações contribui para tornar as informações simétricas com uma menor incerteza dos compradores. A constância da divulgação de informações sobre o produto a ser leiloado reduz o receio da praga do vencedor, o que permite aos potenciais compradores menos informados realizar lances independentes dos lances dos melhor informados. $\mathrm{O}$ resultado poderia ser o aumento da receita do vendedor.

b) Aversão ao risco

Considerar a hipótese de aversão ao risco, e não de neutralidade como no modelo simples, significa supor que os potenciais compradores têm receio de que o custo de aquisição de uma mercadoria possa ser maior do que o benefício.

Riley e Samuelson (1981, p.388, tradução livre) estudaram o leilão de uma só mercadoria e demonstraram que, com a ruptura da hipótese de neutralidade ao risco, não existe equivalência de receita entre os leilões pois o preço de reserva ótimo é uma função decrescente do grau de aversão ao risco do comprador: "Então, no leilão de lqnces elevados, o preço ideal de reserva do vendedor é uma função decrescente do grau de aversão ao risco".

Holt (1980) e Harris e Raviv (1981), que introduzem a aversão ao risco no modelo de Vickrey (1961), também afirmam que a incerteza faz com que os proponentes realizem maiores lances em leilões onde eles pagam os seus próprios lances. Assim, os autores negam o princípio de equivalência de receita com a proposição de que os leilões holandês e de primeiro preço propiciam maiores lances do que os leilões inglês e de segundo preço.

c) Dependência dos lances

A ruptura da hipótese de valor privado ou subjetivo do bem implica que o comprador passe a se preocupar com o fato de estar possivelmente oferecendo um lance acima do valor de mercado. Se a hipótese é de valor comum dos bens, possibilitando a revenda, os participantes passam a considerar na tomada de decisão os lances propostos pelos concorrentes. Essa situação caracteriza a dependência dos lances.

\footnotetext{
${ }^{4}$ Nas últimas grandes privatizações como a da CVRD, o BNDES promoveu uma apresentação para melhor difundir as informações entre os agentes.
} 
A praga do vencedor, própria de leilões com grande número de participantes, onde os lances tendem a ser mais agressivos, faz com que os participantes se tornem avessos ao risco e realizem lances de forma dependente, e não independente como se supôs no modelo simplificado. Bartolini e Cottarelli (1994, p.6) afirmam a este respeito: "o principal resultado, neste caso, é que a equivalência de receita de Vicrey não se sustenta por causa do surgimento dos vícios da praga do vencedor:" O principal resultado, neste caso, é que a equivalência de receita de Vicrey se desmorona por causa do surgimento dos vícios da maldição do vencedor."

Segundo Milgrom e Weber (1982b, p. 869, tradução livre), a dependência na formação dos lances entre os bem informados e os mal informados elimina a praga do vencedor. Os nãovizinhos, que só tem acesso a informações de conhecimento público, receiam estar superestimando o valor do bem. Deste modo, e por reconhecerem suas desvantagens em relação aos compradores melhor informados, evitam realizar ofertas elevadas e preferem lances mais conservadores. Isto se traduz no fato de que os bem informados não sofrem a praga do vencedor, pois podem realizar lances menores também: "Se as empresas não vizinhas realizarem lances com uma estratégia pura (e, portanto, previsível), que especifica uma oferta para cada realização das variáveis de informação pública, a resposta ótima da empresa vizinha é apresentar lance superiores ao máximo do não vizinho."

Os lucros do participante melhor informado aumentam quando ele obtém mais informação sobre o produto e este fato torna-se público, pois os menos informados ficam mais temerosos e realizam lances ainda menores. Tal fato explica porque os lucros do comprador melhor informado são maiores quando ele obtém a informação abertamente do que quando a obtém secretamente.

Este fenômeno é descrito por Milgrom e Weber (1982b) em um modelo de leilão com dois proponentes, no qual o licitante A detém informações privadas enquanto o licitante B tem somente informações públicas no que concerne ao valor $\mathrm{V}$ do objeto que está sendo vendido. Observa-se que o licitante A prefere adquirir qualquer informação adicional publicamente, ao invés de privadamente, porque $\mathrm{B}$ reage à informação extra de $\mathrm{A}$ com propostas mais conservadoras. Por outro lado, B prefere adquirir qualquer informação adicional de forma privilegiada para que A não aumente o lance visando tornar-se mais competitivo.

No modelo de Milgrom e Weber (1982a), a ruptura simultânea das hipóteses de simetria de informações e lances independentes, utilizadas no modelo simplificado, permite contemplar uma situação em que aumenta a margem de lucro do comprador. Milgrom (1979) demonstra que o lance vencedor converge em probabilidade para o valor do objeto leiloado atendidas algumas condições, ainda que qualquer proponente desconheça o valor dos lances realizados e o verdadeiro valor da mercadoria. Há, portanto, evidências empíricas e teóricas de que o comprador com informações exclusivas, especialmente num contexto de dependência entre os lances, alcança maiores lucros nos leilões.

Demonstrada a importância da informação privilegiada para o seu possuidor, cabe observar que, para o governo, convém divulgar informações para conseguir os maiores preços possíveis com a privatização. A este respeito, Hirsherleifer (1988, p. 573, tradução livre) faz o seguinte comentário: "a informação privilegiada que permanece privada mostrou não ter valor social - no sentido de ser puramente redistributiva, não levando a qualquer melhoria nos arranjos produtivos."

Consequências do afastamento das hipóteses do modelo simples para os leilões oral e selado

Leilão oral 
$\mathrm{Na}$ ausência das hipóteses simplificadoras mencionadas, os leilões orais são menos eficientes como maximizadores de receita que os leilões de lance selado.

O leilão do tipo inglês não estimula a atuação da praga do vencedor, uma vez que os proponentes podem acompanhar os lances dos adversários e formar base para saberem se estão ou não realizando lances elevados.

Tal performance difere da do leilão do tipo holandês, onde se estimula a ação da praga do vencedor porque um dos proponentes deve realizar o lance na frente do concorrente. Contudo, segundo Vickrey, o leilão do tipo holandês também é ineficiente do ponto de vista alocativo quando existe grande variação na difusão de informações ou quando os proponentes não são suficientemente sofisticados para identificar o ponto de equilíbrio estratégico.

Segundo Vickrey, em algumas situações particulares, em que os proponentes são mais proximamente homogêneos e sofisticados, o leilão do tipo holandês pode produzir resultados próximos ao do ótimo de Pareto, mas este não é o caso geral.

\section{Leilão selado}

De acordo com Maskin e Riley (1985), a receita esperada pode ser maior nos leilões de lances selados do que nos leilões abertos. Num leilão aberto, os participantes irão fazer propostas até que o preço se iguale à avaliação do bem, enquanto que, nos leilões de lances selados, o receio de não comprar a mercadoria faz com que os proponentes realizem propostas mais agressivas, o que tende a aumentar a receita esperada para o vendedor. Assim, a ruptura da hipótese de neutralidade ao risco, presente no modelo simplificado, indica os leilões de lance selado como aqueles em que se pode aumentar a receita do vendedor porque a praga do vencedor atua mais fortemente.

O leilão de segundo preço, segundo Vickrey (1961), propiciaria maior receita quando os lances não são independentes. Nesta situação, os proponentes realizariam lances no valor do ativo para o proponente. Caso contrário, com a admissão de lances independentes, a receita esperada do leilão de segundo preço seria equivalente à do leilão de primeiro preço.

Para Rothkopft e Harstad (1995), as propriedades do leilão de segundo preço são ainda mais robustas que Vickrey (1961) sugere. Tal proposição se coaduna com a de Milgrom e Weber (1982a) para quem o leilão de segundo preço proporciona maior receita do que o de primeiro preço.

Nos leilões de lance selado, segundo Harris e Raviv ("1981, p. 1494, tradução livre), o leilão de primeiro preço propicia maior receita para o vendedor: "quando os compradores são avessos ao risco, os resultados indicam que o leilão discriminatório domina o leilão competitivo em termos de receita esperada para o vendedor." (p. 1494). No leilão de primeiro preço, os ganhadores pagam seus próprios lances. Riley e Samuelson (1981) também mostram que, quando o comprador é avesso ao risco, o leilão de primeiro preço propicia maior receita para o vendedor do que o leilão de segundo preço. Também para Holt (1980), analisando leilões de lotes de bens, quando os proponentes são avessos ao risco, o leilão discriminatório de primeiro preço resulta em expectativas de receitas mais elevadas para o vendedor.

O leilão de primeiro preço (ou unitário) seria o mais adequado para a venda de ações em grandes blocos. Neste leilão, grandes grupos estariam dispostos a pagar um "prêmio" sobre as ações para garantir o controle, o que não aconteceria numa venda pulverizada.

Contudo, Wilson (1977) aponta o fato de que esta modalidade de leilão está sujeita à manipulação pelos compradores. Como resultado, o preço de venda é menor do que no leilão unitário que ainda tem a vantagem de o preço subir com o aumento do número de participantes. Este autor demonstra ainda que a formação de preço no leilão unitário com lances competitivos permite a atuação do princípio dos grandes números, tanto no sentido econômico como no 
probabilístico. Em trabalho posterior, Wilson (1979, p. 676, tradução livre) afirma que: "em alguns casos, o vendedor pode perder até metade do preço de venda do ativo adotando um leilão de ações". ou ainda: "A expectativa do preço de venda é a fração correspondente de E $\{\mathrm{V}\}$. Observe que, à medida que o número $\mathrm{n}$ de licitantes aumenta, os preços de venda esperados se tornam quase iguais ao valor esperado. Em contrapartida, o preço de venda esperado recebido pelo vendedor em um leilão de ações nas mesmas circunstâncias é metade de $E\{\mathrm{~V}\}$ para qualquer número de licitantes." (p. 684, tradução livre)

Assim, segundo o autor, o leilão discriminatório propriamente dito seria o mais adequado para a venda pulverizada de ações por ensejar a participação de pequenos investidores ao reduzir o risco e o montante de recursos da aplicação. Pulverizar significa vender as ações da empresa em lotes pequenos para milhares de investidores, no país e no exterior.

Em vista dos parágrafos precedentes, dir-se-ia que é importante aumentar o número de participantes nos leilões, mas sem fragmentar o bem a ser leiloado. Contudo, Bartolini e Cottarelli (1994) enfatizam que o debate sobre o formato de leilão que maximiza a receita do governo continua inconclusivo. A nível teórico, há suposições que indicam os leilões de preço uniforme como os mais adequados, pois, ao mitigar a praga do vencedor e propiciar lances mais agressivos, aumentariam a receita para o governo. Todavia, Smith (1966) ressalta que esta condição tem sido observada somente sob hipóteses bastante restritivas, análogas àquelas do modelo proposto por Vickrey. Em pesquisa empírica, o autor compara o leilão de primeiro e de segundo preço e não conclui qual deles proporciona maior expectativa de renda para o vendedor. Este resultado está em coadunância com Feldman e Reinhart (1995a, p.iii), tradução livre) que afirmam: "De 1976 a 1980, o Fundo Monetário Internacional (FMI) vendeu no leilão de lance selado um quinto do seu estoque de ouro em 45 leilões fechados para criar um fundo para ajudar os países em desenvolvimento. O FMI experimentou sistematicamente a técnica, vendendo ouro em 10 leilões de preços uniformes e 35 de preço discriminatório. (...) Os preços de demanda nos leilões de preços uniformes foram mais íngremes e à direita daqueles em leilões de preço discriminatório, mantendo a previsões da teoria dos leilões. Com base nessa regressão, estima-se que o FMI tenha recebido um pagamento médio em seu leilão de ouro com preços discriminatórios que foi 0,06 por cento menor do que o pagamento."

\section{CONCLUSÃO}

A receita esperada pode ser maior nos leilões de lances selados do que nos leilões abertos. Num leilão aberto, os participantes irão fazer propostas até que o preço se iguale à avaliação do bem, enquanto que, nos leilões de lances selados, o receio de não comprar a mercadoria faz com que os proponentes realizem propostas mais agressivas, o que tende a aumentar a receita esperada para o vendedor. Assim, a ruptura da hipótese de neutralidade ao risco, presente no modelo simplificado, indica os leilões de lance selado como aqueles em que se pode aumentar a receita do vendedor porque a praga do vencedor atua mais fortemente. A crença predominante no meio acadêmico parece ser a de que os leilões selados propiciam maiores receitas que o leilão inglês por reduzirem a "praga do vencedor".

Temos ainda que o leilão de segundo preço, segundo Vickrey (1961), propiciaria maior receita quando os lances não são independentes. Nesta situação, os proponentes realizariam lances no valor do ativo para o proponente. Caso contrário, com a admissão de lances independentes, a receita esperada do leilão de segundo preço seria equivalente à do leilão de primeiro preço. 
Além disso, a literatura sugere que medidas como a divulgação de informações e aumento do número de participantes poderiam aumentar a receita obtida em leilões.

\section{REFERÊNCIAS}

AKERLOF, G., (1970). "The market for lemons: Qualitative uncertainty and the market mechanism". Quarterly Journal of Economics, 89: 488-500.

ARTHUR, B. (1996). "Increasing Returns and the Two World of Business". Harvard Business Press.

AZPIAZU, Daniel \& VISPO, Adolfo (1994). "Algunas enseñanzas de las privatizaciones en Argentina". Revista de la Cepal 54, deciembre.

BARTOLINI, L. \& COTTARELLI C. (1994) "Treasury Bill Auctions: Issue and Uses". International Monetary Fund. WP/95/135.

BAUMOL, W. (1982) "Contestable Markets: an Uprising in the Theory of Industry Structure". The American Economic Review”,72:1-15

BIKHCANDANI, S., \& HUANG, C. (1989) "Auctions with Resale with Markets: an exploratory Model of Treasury Bill Markets", Review of Financial Studies 2: 311-339.

BIKHCHANDANI, S., \& HUANG, C. (1993) "The Economics of Treasury Securities Markets", Journal of Economic Perspectives 7:3, 117-134.

BISHOP, Matthew \& KAY, John. (1988) Does Privatization Work? Lessons from the U.K. London Business School, London.

BNDES (1996). "Relatório de Atividades". Rio de Janeiro.

BNDES. (1991) "Programa Nacional de Desestatização - Legislação Básica”. Rio de Janeiro, Mímeo.

BNDES (1995). "Relatório de Atividades". Rio de Janeiro.

BORCHERDING, T.E., BUSH, W.C. \& SPANN, R.M. (1977). "Budgets and bureaucrats: The sources of government growth", 211-228. Durham: Duke University Press.

BORENSZTEIN E. \& KUMAR M. S. (1991) "Proposals for Privatization in Eastern Europe". International Monetary Fund. WP/91/36.

BRASIL, Decreto no 2.594, de 9 de setembro de 1997, que dispõe sobre o Programa Nacional de Desestatização e dá outras providências, Diário Oficial [da] República Federativa do Brasil, Poder Executivo, Brasília, DF, DE 18/05/1998, P. 14. 
BRUEKNER, J. K. \& O'BRIEN, K. M. (1989). Modeling government behavior in collective bargaining: A test for self-interested bureaucrats. Public Choice 63: 15-49.

BULOW, J. \& ROBERTS, J. (1989) The simple Economics of Optimal Auctions. Journal of Political Economy, 97:1060-1090.

COASE, R. H. (1960) "The Problem of Social Cost". The Journal of Law and Economics, 3: $1-44$.

COASE, R. H. (1971) “The Federal Communications Commission”. The Journal of Law and Economics. XIV:146-165.

CORPORAÇÃO FINANCEIRA INTERNACIONAL (1995). Privatización. Princípios y Practicas. Miembro del Grupo del Banco Mundial. Washington, D.C.

COX, J. C., SMITH V. L., WALKER J. M. (1984) Theory and Behavior of Multiple Unit Discriminative Auctions. The Journal of Finance, 39: 983-1083.

FELDMAN R. A. \& MEHRA R. (1993) "Auctions: Theory and Possible Applications To Economies in Transition”. International Monetary Fund. WP/93/12.

FELDMAN R. A. \& REINHART V. (1995a) "Flexible Estimation of Demand Shedules and Revenues under Different Auction Formats". International Monetary Fund. WP/95/116.

FELDMAN R. A. \& REINHART V. (1995b). "Auction Format Matters: Evidence on Bidding. Behavior and Seller Revenue". International Monetary Fund. WP/95/47.

GERCHUNOFF, P. \& CÁNOVAS, G. (1994) "Las privatizaciones en la Argentina: impacto micro e macroeconômicos”. Santiago, Cepal - Séries Reformas de Política Pública, 21.

GERCHUNOFF, P. (1992) "Las privatizaciones en Argentina". Washington, D.C., BIRD Série de Documentos de Trabalho, 121.

GERSHENFRON, Alexander (1962). "Economic Backwardness. Historical Perspective". Cambridge, Mass.

GOETZMANN W. N., \& SPIEGEL M. (1995) "Private value components, and the winner's curse in an art index". European Economic Review 39: 549-555.

GROSSMAN, S. (1977) "The Existence of Futures Markets, Nosy Rational Expectations and Informational Externalities". Review of Economic Studies 44: 431-449

HARRIS, Milton \& RAVIV A. (1981) “Allocation Mechanisms and The Design of Auctions". Econometrica, vol 49, n6 p.1477-1499. 
HEMMING R. \& MANSOOR A. M. (1988) "Privatization and Public Enterprises". International Monetary Fund. Occasional Paper $\mathrm{n}^{\circ}$ 56. Washington D.C.

HENDRICKS Kenneth \& PORTER H. Robert, (1988) "An Empirical of an Auction with Asymmetric Information". American Economic Review, 78: 865-895.

HIRSHELEIFER, Jack. (1971) "The private and Social Value of Information an the Reward to Incentive Activity". The American Economic Review, 61: 561-574.

HOLT, C. (1980) "Competitive Bidding for Contracts Under Alternative Auction procedures". Journal of Political Economy, 88: 433-445.

IBOVESPA (1990) “O caminho da privatização”. Bolsa de Valores de São Paulo.

KAGEL, John H. \& LEVIN, Dan. (1986) “The Winner's Curse and Public Information in Common Value Auction. The American Economic Review, 75: 894-920.

MÁLAGA, Tomás (1997) "Privatização e Déficit Financeiro". Gazeta Mercantil, 7 de outubro, A-3.

MARLOW, M. L. \& ORZECHOWSKI, W. (1996) "Public sector unions and public spending". Public Choice 89: 1-16.

MASKIN, E. S. M. and RILEY, J.G. (1985) “Auctions Theory with Private Values" in AEA Papers and Proceeding.

MAYER, C.P., \& MEADOWCROFT. (1985) "Selling Public Assets: Techniques and Financial Implications". Fiscal Studies (Oxford), vol. 6 , p. 42-55;

McAFEE, R. P. \& McMILLAN J. (1987) “Auction and Bidding”. Journal of Economic Literature 25, p. 699-738.

MELLO, M.F. (1994) "Privatização e Ajuste Fiscal no Brasil". Pesquisa e Planejamento Econômico, IPEA, 24: 445-518.

MILGROM Paul \& WEBER, Robert J. (1982a) "A Theory of Auctions and Competitive Bidding”. Econometrica, 50: 1089-1122.

MILGROM Paul \& WEBER, Robert J. (1982b) "The Value of Information in a Sealed-Bid Auction" in Journal of Mathematical Economics 10: 105-114.

MILGROM, Paul (1979) “A Convergence Theorem for Competitive Bidding with differential information”. Econometrica, 47: 679-688

MILGROM, R. Paul (1981) "Rational Expectations, Information Acquisition and Competitive Bidding”. Econometrica, 49: 921-943. 
PAGANO, Marco \& RÖEL A. (1991). "Auction and Dealership Markets. What's the difference?” European Economic Review 36: 613-623.

RILEY J. \& SAMUELSON W. F. (1981) "Optimal Auctions". The American Economic Review, 71: 381-92.

THIEL, Stuart E. (1988) "Some Evidence on the Winner's Curse”. The American Economic Review, p. 865-895.

VICKRES, J. \& YARROW G. (1995) "Privatization: An Economic Analysis”. The MIT Press.

VICKRES, J. \& YARROW G. (1991) "Economic perspectives in privatization". Journal of Economic Perspectives, 5: 111-132.

VICKRES, J. (1995) “Concepts of Competition”. Oxford Economic Papers 47: 1-23.

VICKREY, W., (1961) "Counterspeculation, Auctions, and Competitive Sealed tenders". Journal of Finance, 16: 8-37.

WALTERS, A. (1992) "Liberalização e Privatização". Documento apresentado no Seminário sobre Política Fiscal, patrocinado pelo Banco Mundial realizado na Escola de Administração Fazendária - ESAF, no período de 10 a 12/06/92.

WILSON, Robert (1977) “A Bidding Model of Perfect Competition”. Review of Economic Studies, 4: 511-518.

WILSON, Robert (1979) “Auctions of Shares”. Quarterly Journal of Economics, 93: 675-698.

WORLD BANK (1988). "World Development Report”. The World Bank Washington, D.C.

WORLD BANK (1989) “Brazil Prospects for Privatization”. Report no. 7550-BR.

WORLD BANK (1993). "Argentina's Privatization Program. Experience, Issue, and Lessons". (Development in Practice). Washington, D.C.

WORLD BANK (1997) "Global Economic Prospects and the Developing Countries". The World Bank Washington, D.C. 